\title{
Patient Referral As a Quality Outcome of Occupational Health Practice At The Workplace in Turkey
}

\author{
Arif Hikmet Çımrın ${ }^{1}$, Esra Aydın Özgür ${ }^{(\infty)}$, Nur Şafak Alıcı ${ }^{\circledR}$ \\ 'Dokuz Eylül University, Medical School, Department of Occupational Medicine, İzmir, Turkey \\ Address for Correspondence: Esra Aydın Özgür, E-mail: esraaydin 08@hotmail.com \\ Received: 21.10.2019; Accepted: 18.12.2019; Available Online Date: 27.01.2020 \\ CCopyright 2019 by Dokuz Eylül University, Institute of Health Sciences - Available online at www.jbachs.org
}

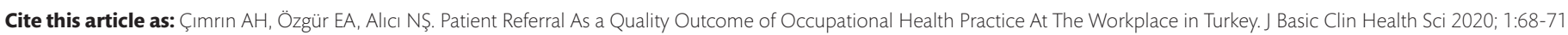

\begin{abstract}
Objective: In the determination of the Workplace Health and Safety management system effectiveness, the rates of the occupational diseases, accidents or work-related diseases are the most commonly used outcome indicators. Occupational physicians (OP) may decide on consultation with various indications including diagnosis of occupational disease.

Aims: The content of the referral from the workplace affects the accuracy of the consultation to be done.

Methods: This study evaluates the contents of the referral documents of the patients who applied to our clinic and analyzes the approach of the OP to the referral process and health surveillance in the workplace.

Results: 412 (32\%) cases referred by OP from 1288 patients who applied were evaluated. The most common reasons for the referral were abnormal diagnostic test results (43\%) and evaluation for the possible occupational disease diagnosis (35\%). The preliminary diagnosis of the occupational disease was present in the $55.3 \%$ of the referral documents. Most of the referrals ( $82.5 \%$ ) did not contain the information about the complaints, medical and occupational history, physical examination findings and resume of the patients. There was no workplace environment measurements (93.4\%) and no explanation regarding the hazards which patients were exposed in the workplace (74\%) in most of the referral documents.
\end{abstract}

Conclusion: Our findings suggest that OP have deficiencies in collecting and evaluating data during the health surveillance of the employees, and workplace health and safety management system should improve the function of enhancing its effectiveness.

Keywords: occupational health, referral, workplace

\section{INTRODUCTION}

Occupational and/or work-related accidents or diseases occur in approximately more than 2.3 million people annually worldwide, resulting in approximately 350,000 deaths for these cases (1). Because with the comprehensive preventive actions and programs in workplace work-related diseases and accidents can be prevented, the rates of the occupational diseases, accidents or work-related diseases are the most commonly used outcome indicators in the determination of the workplace health and safety management system effectiveness (2).

In this context, the role and functions of the occupational physicians (OP) are critical. OP plays an important role in occupational health and safety (OHS) management systems to improve the working environment by taking preventive measures with the aim of protecting and improving employee health. The main responsibilities of OP are to determine eligibility for work, to assess occupational risks, to improve working conditions by reducing the risk, early diagnosis of occupational diseases, rehabilitation at work, to assess the return to work $(3,4)$. Therefore, Turkey's law gives responsibilities to occupational physicians such as planning and conducting the risk analysis and the health surveillance in the workplace (5).

Except for OP; physicians in primary, secondary and tertiary health institutions may diagnose the occupational diseases in Turkey. Occupational diseases hospitals and occupational diseases clinics work like tertiary care institutions. Employees apply individually to the occupational diseases clinics on their demands by appealing to the Social Security Institution.

OP may need medical consultations with other physicians not only for diagnosis and treatment of occupational diseases but also for 
indications such as job suitability, return to work or rehabilitation. For this reason, the purpose and contents of the consultations differ from those of other physicians for therapeutic purposes. OP may decide on a consultation with an occupational disease specialist in any situation that is considered to be complicated, especially when a health problem arises, particularly in the search for a diagnosis or relation to the occupation (3).

Due to the nature of the problems to be resolved, it is known that OP has its own specific difficulty of cooperating with another physician. In a study investigating the tendency of OP to consult with specialist physicians about occupational health; it is emphasized that the lack of clear information about the mutual duties of physicians is an important factor in communication (6). However, taking into account the sensitivity of the subject, it is recommended that OP consider ethical rules in communication with other physicians, if not legally defined (7).

When OP decides on consultation, the concept of referral the employee to the occupational diseases specialist emerges. Referral from the workplace affects the accuracy of the consultation to be made. The indications and procedures for referral must be in the ethical rules and the existing legal framework. The first step of the referral process should be to inform the employee. The reason for referral should be explained by sharing the present findings with the case. The approval of the employee must be obtained in the written form; if not possible, verbal approval should be obtained and taken into the registration. Attention should be paid to the confidentiality of information in the workplace. After informing the workplace human resources unit as "referral for health reason", the patient should be referred to consultation clinic with the created referral form. In the referral form, the reasons for referral (main problem), the hazards of the work, the materials used and the content of the work, the health records starting from the entry to work and the workplace environment assessments of the hazards and the possible diagnosis (if available) should be clearly indicated (8).

In the light of all these information, by evaluating the contents of the referral documents of the patients who applied to our clinic, which acts as tertiary care health unit, we aimed to evaluate OPs attitudes toward medical evaluation and referral procedures and approaches to health oversight at the workplace.

\section{METHODS}

The referral documents of 1288 patients who applied to our outpatient clinic between 2014-2017 were evaluated and the documents of the cases referred by the occupational physicians were evaluated according to the following criteria; a. Workplace name and address in the referral documents; $b$. The line of the work of the case; c. Referral location and address; d. Purpose of the referral; e. Preliminary diagnosis if available and what it is; $\mathrm{f}$. Complaints of the case, physical examination findings, and history; g. Work history, old workplace environment measurements, and hazard identification; h. Form attachments (medical records including entry to work and periodic examinations, laboratory measurement results, $x$-ray, audiometer, respiratory function test, material safety data sheets (MSDS) and other toxicological information for used materials, workplace environment measurement results, workplace risk analysis report); i. Name, address and contact information of the occupational physician.

Statistical analysis was performed using the PASW Statistics for Windows (SPSS Inc. Version 18.0, Released 2009, Chicago, USA) statistical package program. The frequencies of the data obtained by counting were calculated.

\section{RESULTS}

We found that $32 \%$ (n: 412) of 1288 patients who applied to our clinic were referred by OPs and the cases were working in 98 different establishments.

When the sectors of the cases were examined in their occupational history; ceramic sector ( $\mathrm{n}: 172)$, dental prosthesis ( $\mathrm{n}: 33)$, mining ( $\mathrm{n}$ : $43)$, shipyard-ship construction ( $\mathrm{n}: 26)$, health sector ( $\mathrm{n}: 13$ ) and call center operators ( $n: 8)$ were among the most frequent lines. The distribution of the cases according to the sectors they work in is given in Figure 1.

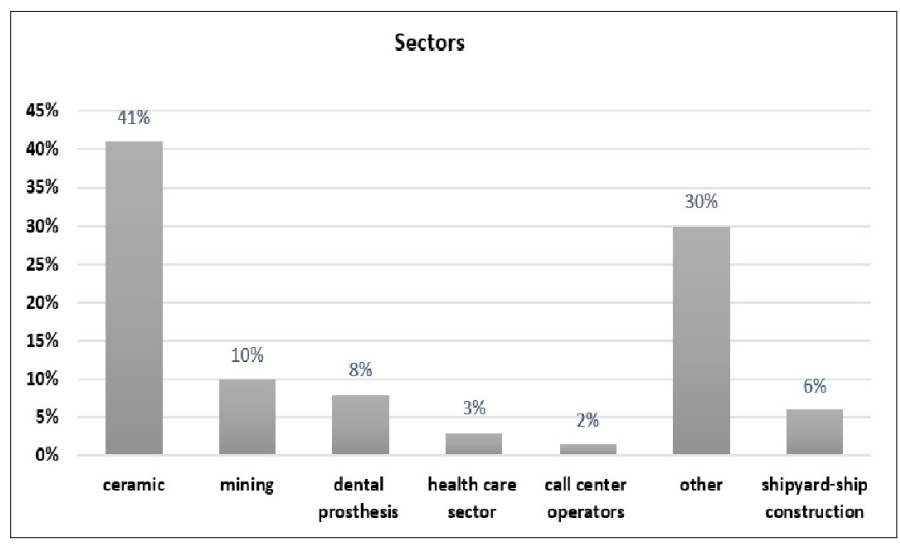

Figure 1. Sectoral distribution of the cases referred by occupational physicians

In $64.6 \%$ of the cases, the sectors of the patients was indicated in the referral documents. Although the names of the workplaces were mentioned in high rates (87.6\%), the address or contact information about the workplace was only in $33.7 \%$ of them.

The name of the institution referred was indicated in $97.1 \%$ of the cases. However, specific details such as the name, title/position or address of the referrer were present in only $25 \%$.

When the referral reasons were evaluated, the most frequent referrals order were; abnormal laboratory test results of the patient (43\%), assessment of the possible occupational diseases (35\%), check for occupational diseases (6.6\%), assessment of eligibility / return to work (5.8\%), no information about the referral $(4,9 \%)$, decrease in working capacity $(2.2 \%)$, referral due to the suggestion of an another physician (1.7\%) (Table 1). 


\begin{tabular}{lcc}
$\begin{array}{l}\text { Table 1. Distribution of the causes of the referrals in } \\
\text { referral documents }\end{array}$ & & \\
\hline Causes of the referrals & $\%$ & $\mathbf{n}$ \\
\hline Abnormal laboratory test results & 43,9 & 181 \\
Assessment of the possible occupational diseases & 35 & 144 \\
Check for occupational diseases & 6,6 & 27 \\
Assessment of eligibility / return to work & 5,8 & 24 \\
No information about the referral & 4,9 & 20 \\
Decrease in working capacity & 2,2 & 9 \\
Referral due to the suggestion of an another physician & 1,7 & 7 \\
\hline
\end{tabular}

$55.3 \%$ of referral documents had a preliminary diagnosis, $44.7 \%$ had no preliminary diagnosis. When examined in terms of preliminary diagnosis systems, respiratory system diseases, otorhinolaryngology, musculoskeletal system diseases were detected in the first three systems according to their frequency. The most frequent diagnoses were pneumoconiosis, hearing loss, asthma, lumbar disc herniation and lead intoxication when analyzed in terms of diagnosis; the other causes were found as $6.5 \%$. The preliminary diagnoses and their frequencies in the referral documents are given in Table 2.

Most of the referrals (82.5\%) had no information about complaints, history, physical examination findings, and resume. Results of the laboratory examinations in $55.3 \%$ of the cases were included in the referral documents. The ones added or recorded in the referral documents of these diagnostic laboratory examinations are classified according to the order of frequency; results were x-ray $(49,3 \%)$, respiratory function test (7,3\%), blood tests (3\%) and audiometry (1\%).

The majority of the referral documents had no workplace environment measurement (93.4\%) and no description of the hazards (74\%) that the patients were exposed to in their workplaces. In only $3.9 \%$ of the cases, there were results related to the health record of the case, the MSDS of the materials used and/or the workplace environment measurement together with the referral document.

In the majority of the referral documents (93.4\%), the name of the occupational physician referring to the case was observed, while the postal / e-mail address of the occupational physician was found as $20.6 \%$ and communication information such as telephone/fax number as $16.3 \%$.

When examined preliminary diagnosis in terms of systems; there were diseases related to respiratory system diseases (n: 143), otorhinolaryngology (n: 27), musculoskeletal (n: 26), intoxications (n: 13), dermatologic (n: 10), neurologic ( $\mathrm{n}: 5)$ and oncology (n: 3). There were preliminary diagnoses such as pneumoconiosis ( $n$ : 114), hearing loss ( $\mathrm{n}: 24)$, asthma ( $\mathrm{n}: 20)$, lumbar disc herniation (n: 15), lead intoxication (n: 9) and other causes (n: 26) (Table 2 ).

The rate of the preliminary diagnosis, which was indicated by the occupational physician as the referral cause on the referral document, being final diagnosis was 52.6\% (120 cases). As a result of the evaluation in our clinic, 56 (\% 24.6) of the cases with preliminary diagnosis on referral document obtained an additional diagnosis.
Table 2. Distribution of the preliminary diagnoses in referral documents according to systems and diagnosis

\begin{tabular}{ll}
\hline Systems (\%) & Diagnosis (\%) \\
\hline Respiratory System $(35,5)$ & Pneumoconiosis $(27,5)$ \\
Otorhinolaryngology $(6,5)$ & Hearing Loss $(6)$ \\
Musculoskeletal System $(6,3)$ & Asthma $(5)$ \\
Intoxication $(3,1)$ & Lumbar Disc Herniation $(3,5)$ \\
Dermatological $(2,5)$ & Lead Intoxication $(2)$ \\
Neurological $(1,2)$ & Other $(6,5)$ \\
Oncology $(0,7)$ & \\
\hline
\end{tabular}

\section{DISCUSSION}

Only one third of the patients who applied to our clinic were referred by OP; the remaining two third were referred by social security institution or secondary and tertiary care health institutions. The referral from the OP is important because it means that OP defines the problem in the workplace and with this information OP initiates the process of interfering with the workplace health and safety practices. However, the fact that two third of the cases were not referred by OP could be related to the inability to detect a health problem in the workplace or any other adverse reasons related to the workplace.

The final diagnoses of the cases were known occupational diseases such as pneumoconiosis, asthma and hearing loss, occurring due to the exposure in various workplaces including ceramic, dental prosthesis and metal sectors. However, call center as a growing business area for our country was included in our case group because of the noise and ergonomic risk it contained. Referral due to any reason except occupational disease suspicion was very rare. This seems to be related to the requirement of the occupational physician to legally refer to one of the occupational diseases clinics in case of the diagnosis or suspicion of the occupational diseases.

However, the lack of other indications for referral causes OPs to be questioned for their tendency for the consultations. When we evaluate the referral process, the reluctance of OPs to talk to our clinic by telephone or personally in advance of referral was striking. This finding also strengthens the possibility of referral because of the legal necessity. The tendency of cooperation due to legal necessity has also been discussed in other studies (9).

The lack of contact information for the workplace and the occupational physician in the referral documents of the cases may also be related to the lack of a structured referral form, but may also be indicative of "disregarding the situation" resulting from the referral requirement. There was no reason for referral stated on the referral documents in $5 \%$ of the patients. The referral of a case to the tertiary level health center for "purposeless" referral from the workplace shows the medical inconstancy of the occupational physician. The fact that the referral rate is very high as a result of the abnormal laboratory findings is reinforcing this possibility. The suspicious expressions mentioned in the reports of routine diagnostic laboratory test examinations such as chest $\mathrm{x}$-ray and spirometric evaluation obtained under periodic health examination become the reason for referrals, and these 
patients are preferred to be referred rather than subjected to a comprehensive evaluation in the workplace. Within the referral documents, the results of workplace environment measurement analysis and risk analysis are not found in the majority of the cases.

These findings, when taken as a whole, suggest that physicians in the workplace are confused about the health of the workers and that they do not have sufficient knowledge and experience on the path they should follow when referring to a consultation at the same time. However, it is also possible that the occupational physician does not have the information about the results of the working environment measurement analysis of the workplace and the medical records of the patient, which should be kept in the workplace. The absence of the systematic review of the working conditions, work histories, complaints, medical histories, physical examinations and findings of the case in any referral documents support this judgement.

Another issue that needs to be discussed is the need for the patient to be informed and approved for the referral. None of the cases we evaluated had information on this issue in the referral documents. Because OPs in Turkey are legally obliged to refer the patients to the occupational diseases clinic when the doubts for the occupational diseases arise, physicians may not have taken the person's consent. However, informing is important to enforce the legal rights of a person to work and health and is an ethical practice (7).

As a result, although OP has a key role in the protection of health in the workplace, our findings seem to suggest that occupational physicians have deficiencies in planning health surveillance at the workplace, interpreting the results, and managing employees' health at the workplace.

Employee's need for a health center requires special attention. The content of the referral document gains importance in concluding the consultation successfully. Referral indications and standardization of the referral process seem to be one of the main factors increasing the quality of consultation (9).

\section{REFERENCES}

1. International Labour Office (2014) Safety and Health at Work: A Vision for Sustainable Prevention. International Labour Office: XX World Congress on Safety and Health at Work, Frankfurt, Germany. https://www.ilo.org/wcmsp5/groups/public/---ed_protect/--protrav/---safework/documents/publication/wcms_301214.pdf

2. Good Practice in Occupational Health Services: A Contribution to Workplace Health. WHO Regional Office for Europe. EUR/02/5041181 2002. http://www.euro.who.int

3. de Bono AM. Communication between an occupational physician and other medical practitioners-an audit. Occup Med 1997;47:349356. [CrossRef]

4. Ikonen A, Rasanen K, Manninen P, et al. Work-Related Primary Care in Occupational Health Physician's Practice. J Occup Rehabil 2012;22:88-96. [CrossRef]

5. İşyeri Hekimi ve Diğer Sağlık Personelinin Görev, Yetki, Sorumluluk ve Eğitimleri Hakkında Yönetmelik. https://www.mevzuat.gov.tr/Metin. Aspx?MevzuatKod=7.5.18615\&Mevzuatlliski=0\&sourceXmlSearch

\section{CONCLUSION}

In order to overcome these constraints, it may be useful to establish the standards of OP education, indications of referral from the workplace, and what should be considered when referring with the health surveillance planning and implementation. It has been reported that communication between physicians is another important factor that speeds up the consultation (10). It may be useful to identify training programs and common rules of practice to increase the success of consultation and collaboration among physicians when consultation decisions are made to resolve the problems they face (6).

\section{Key Points}

- OP may decide on a consultation with an occupational disease specialist in any situation.

- The content of the referral document gains importance in concluding the consultation.

- Referral standardization of the consultation process may be useful to establish the standards of OP education and indications of referral from the workplace.

Compliance with Ethical Standards: Ethics Committee approval was obtained from the Ethics Committee of Dokuz Eylül University Medical Faculty University (Decision no: 2019 / 03-47)

Peer-review: Externally peer-reviewed.

Author Contributions: Concept - AHÇ; Design - AHÇ, EAÖ; Supervision - AHÇ, EAÖ; Fundings - AHÇ, NŞA; Materials - AHÇ, NŞA; Data Collection and/or Processing - AHÇ, NŞA; Analysis and/or Interpretation - AHÇ, NŞA; Literature Search - AHÇ, EAÖ; Writing Manuscript - AHÇ, EAÖ; Critical Review - AHÇ, EAÖ

Conflict of Interest: No conflict of interest was declared by the authors

Financial Disclosure: The authors declared that this study has received no financial support.

6. De Buck PDM, Van Amstel RJ, Buijs PC, et al. Communication between Dutch rheumatologists and occupational physicians in the occupational rehabilitation of patients with rheumatic diseases. Ann Rheum Dis 2002;61:62-65. [CrossRef]

7. BMA. The occupational physician; 2018. https://www.bma.org uk/advice/employment/occupational-health/the-occupationalphysician

8. University of Leicester. Division of Human Resources, Occupational Health Service. Managers' Guide to making an Occupational Health Referral; 2018. https://www2.le.ac.uk/offices/hr/docs/policies/ohmg.pdf

9. Persechino B, Fontana L, Burest G, et al. Collaboration of occupational physicians with national health system and general practitioners in Italy. Ind Health 2017;55:180-191. [CrossRef]

10. Thorsen $\mathrm{O}$, Hartveit M, Baerheim A. The consultants' role in the referring process with general practitioners: partners or adjudicators? a qualitative study. BMC Fam Pract 2013;14:153. [CrossRef] 